\title{
Prototipe Sistem Deteksi Jantung Manusia dan Lokasi Berbasis Internet of Things (IoT)
}

\author{
Almira Budiyanto*, Ardymas Jati Putu Mardana \\ Program Studi Teknik Elektro, Universitas Islam Indonesia, Yogyakarta \\ * email: almira.budiyanto@uii.ac.id
}

\begin{abstract}
The deaths caused by heart and blood vessel diseases reached 17.7 million people or 32.26 percent of total deaths in the world. The representation of heart health can be seen from the number of heart rate (HR) and oxygen saturation (SpO2). The purpose of this study is to determine the condition of the human body through the number of heartbeats and SpO2 using the MAX30100 sensor and to be able to find out the location of the patient via GPS Adafruit Ultimate Breakout. GPS calibration uses two calculation methods, namely using the Haversine formula and using the distance measurement feature on Google Earth. The method is then compared to get the difference between the coordinates obtained by the smartphone GPS as a reference with the patient's GPS. The HR measurement calibration on the MAX30100 sensor is then compared with the pulse on the wrist for accuracy.. The results of this study indicate the level of coordinate accuracy obtained by GPS Adafruit is not more than 5 meters. The average HR accuracy value is 98,23 percent and the SpO2 calibration results get an accuracy of 98,99 percent. The waiting time required for the GPS to receive coordinates from the satellite with the GPS condition uncovered by the casing is about 7 to 13 minutes, while when the casing is closed the GPS cannot get the coordinates. MAX30100 can work optimally and obtain accurate values when the patient is in a relaxed position and does not do too much movement.
\end{abstract}

Keywords — GPS Adafruit, Heart Rate, SpO2.

\section{Pendahuluan}

Salah satu penyakit berbahaya yang menimbulkan kematian pada penderitanya adalah penyakit jantung. Berdasarkan data The Institute for Health Metrics and Evaluation (IHME) (2016) menunjukkan bahwa kematian di dunia yang disebabkan oleh penyakit jantung dan pembuluh darah mencapai 17,7 juta jiwa atau sekitar $32,26 \%$ total kematian di dunia [1]. Jantung merupakan salah satu organ vital manusia. Representasi kesehatan jantung dapat dilihat dari jumlah detak jantung (HR) dan saturasi oksigen (SpO2). Usia dan kondisi tubuh dapat mempengaruhi jumlah detak jantung dan $\mathrm{SpO} 2$ pasien. Ketika fungsi jantung tidak normal maka akan timbul kelainan atau penyakit pada tubuh manusia. Untuk orang dewasa normal di atas 18 tahun, detak jantung harus berada dalam kisaran 60-100 BPM tergantung dengan kondisi fisik dan usia, sedangkan untuk anak-anak berada dalam kisaran 70-100 BPM. Saat ini pengecekan detak jantung dilakukan secara manual pada pergelangan tangan per menit. Pengukuran tingkat saturasi oksigen (SpO2) dapat digunakan untuk deteksi dini gejala hipoksia yaitu kondisi dimana kadar oksigen dalam darah terlalu rendah.

Alat ukur digital detak jantung dan $\mathrm{SpO} 2$ yang dijual dipasaran tidak dapat dipantau dari jarak jauh. Untuk mendapatkan informasi tersebut diperlukan sistem yang dapat merekam informasi denyut jantung dan saturasi oksigen serta dapat dipantau di daerah yang terpencil [2]. Pemantauan jarak jauh kondisi tubuh pasien terkini dapat membantu tenaga medis maupun keluarga mengetahui kondisi terkini pengguna [3]. Kemajuan teknologi dibidang kesehatan yang berkembang sangat pesat menciptakan alat-alat kesehatan berbasis nirkabel yang dapat dipantau dari jarak jauh. Salah satu implementasinya adalah E-Health yang menurut WHO 
sebagai pemanfaatan perangkat elektronik untuk mengelola sumberdaya kesehatan dan pemeliharaan kesehatan.

Berdasarkan latar belakang tersebut, penelitian tentang sistem komunikasi dengan membuat prototype instrumen alat yang dapat mengirimkan informasi detak jantung, $\mathrm{SpO} 2$ dan lokasi seseorang (pasien) menggunakan sensor MAX30100, GPS dan ESP826 ke smartphone melalui koneksi internet. Koneksi internet pada prototipe memerlukan acces point wifi yang stabil. Pasien juga dapat mengetahui kondisinya pada layar LED yang terpasang di pergelangan tangan. Prototipe dapat digunakan untuk pasien dengan aktivitas rendah (posisi duduk atau tidur) di rumah sakit maupun pasien yang sedang dalam perjalanan ke rumah sakit menggunakan ambulance agar dapat dipantau oleh dokter maupun keluarga. Apabila detak jantung dalam kondisi tertentu, notifikasi akan dikirim ke pemantau melalui koneksi internet dan ke LED pasien. Orang di sekitar pasien dapat mengetahui kondisi pasien dan pemantau dapat langsung menuju lokasi pasien berdasarkan koordinat dari GPS yang terpasang, sehingga pasien dapat segera mendapatkan pertolongan. Penelitian ini perlu dilakukan agar monitoring kondisi pasien dapat segera diketahui oleh dokter maupun keluarga dari jarak jauh.

\section{Metode Penelitian}

\subsection{Perancangan Perangkat Lunak}

Pada tahap ini, perancangan perangkat lunak menggunakan software Arduino IDE sebagai pemroses data menggunakan D1 Mini dan aplikasi Blynk untuk menampilkan data di smartphone. Untuk menghubungkan D1 Mini dengan Blynk, terdapat pin/token khusus yang harus dimasukkan ke dalam program. Terdapat dua sensor utama dalam penelitian ini yaitu GPS dan MAX30100. Agar MAX30100 dapat menampilkan data $H R$ dan SpO2, memerlukan library dari Oxullo Intersecans untuk Maxim-IC MAX30100 yang dapat diunduh melalui Library Manager Arduino IDE. Cara kerja sistem dari sensor MAX30100 dalam penelitian ini ditunjukkan pada Gambar 1.

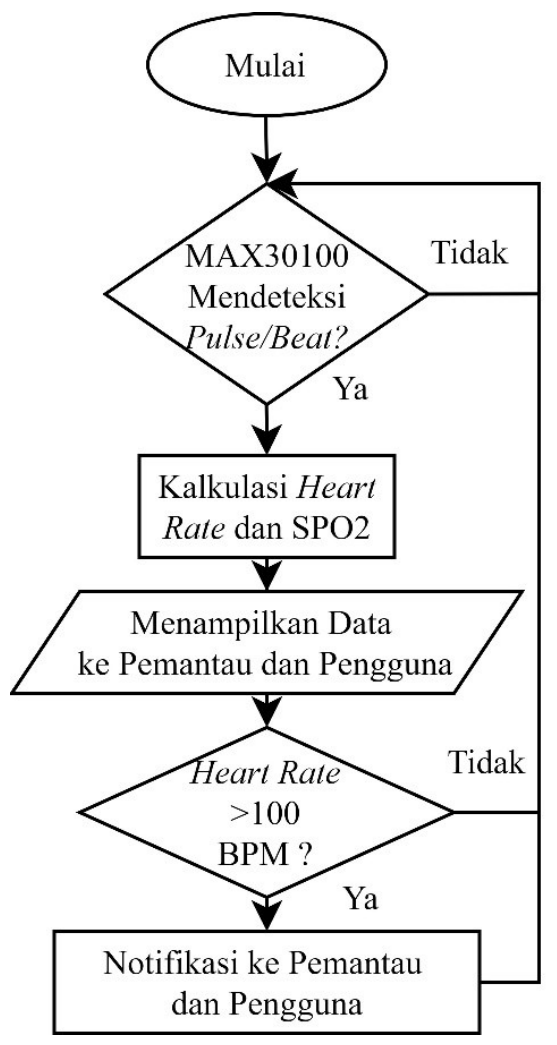

Gambar 1. Cara kerja MAX30100 
GPS dapat menampilkan beragam navigasi seperti jam, tanggal, koordinat, kecepatan dalam knots, sudut, ketinggian, satelit dan lain lain. Namun, pada penelitian ini hanya menampilkan koordinat longitude dan latitude dalam derajat atau degrees. Cara kerja sistem GPS dalam penelitian ini seperti Gambar 2.

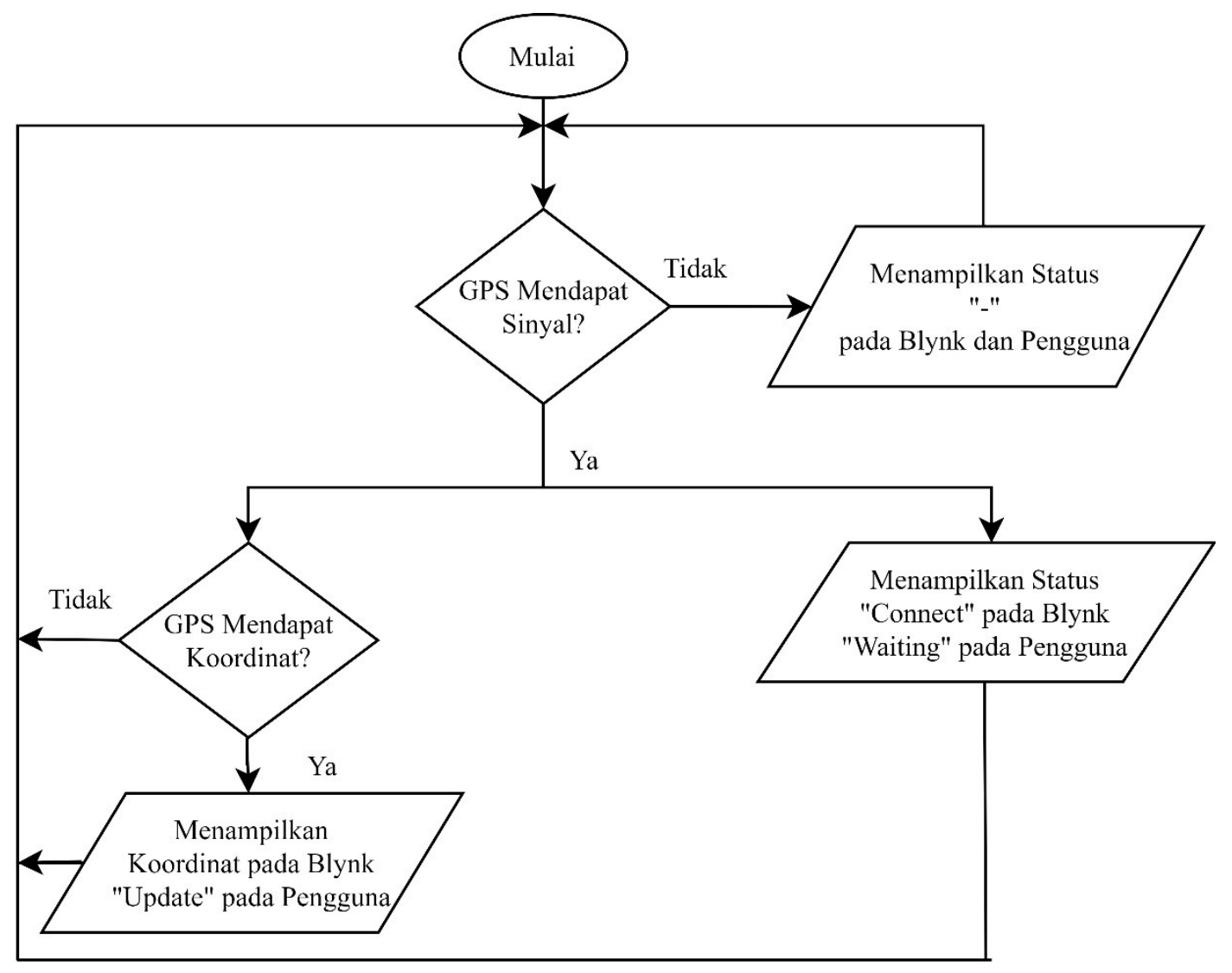

Gambar 2. Cara kerja GPS

Tampilan utama pada aplikasi Blynk ditunjukkan pada Gambar 3 dan notifikasi detak jantung ditunjukkan pada Gambar 4.

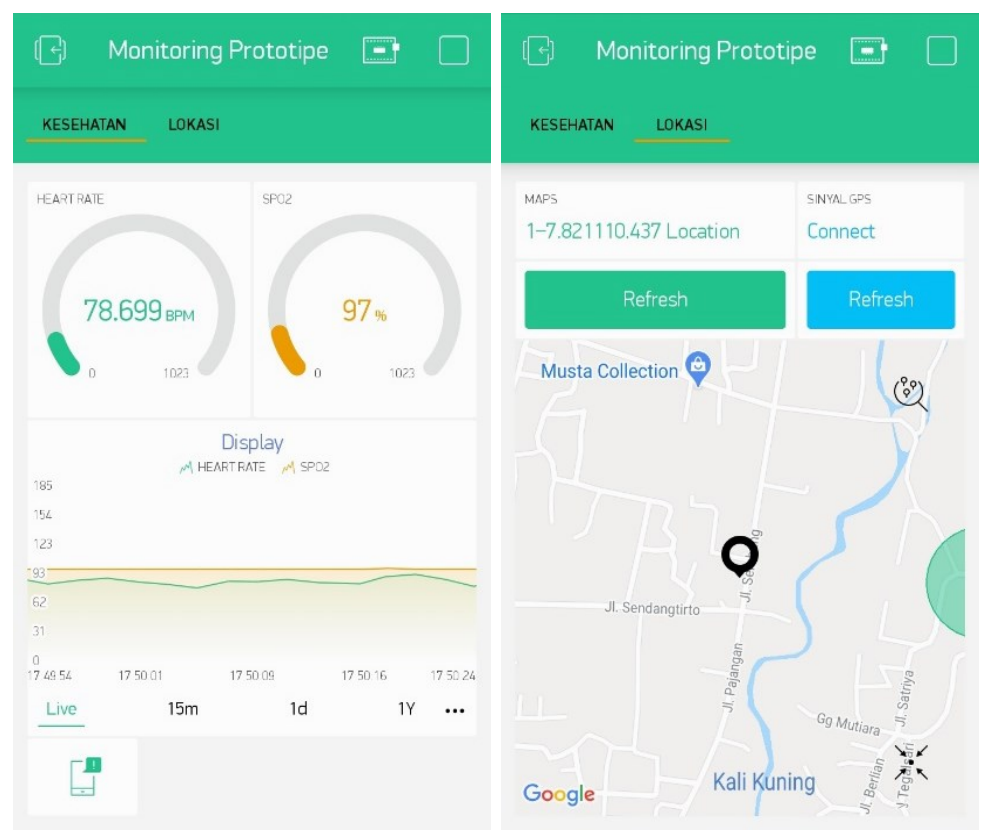

Gambar 3. Tampilan Blynk 


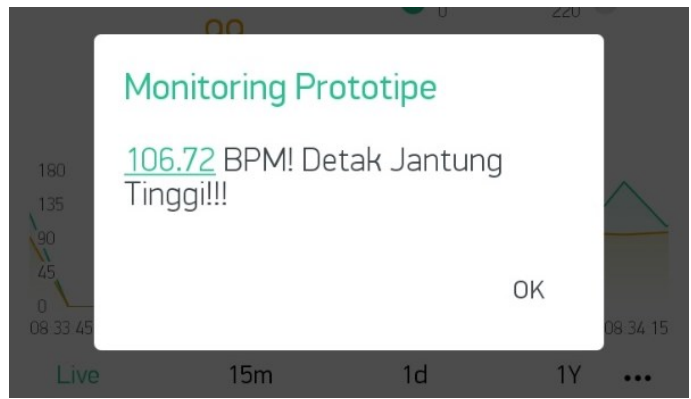

Gambar 4. Tampilan notifikasi Blynk

\subsection{Perancangan Perangkat Keras}

Terdapat beberapa komponen pada penelitian ini yaitu, OLED 0.96 Inch, sensor MAX30100, GPS dan D1 Mini sebagai pengolah data. Pada Gambar 5 menunjukkan skema yang digunakan pada penelitian ini.

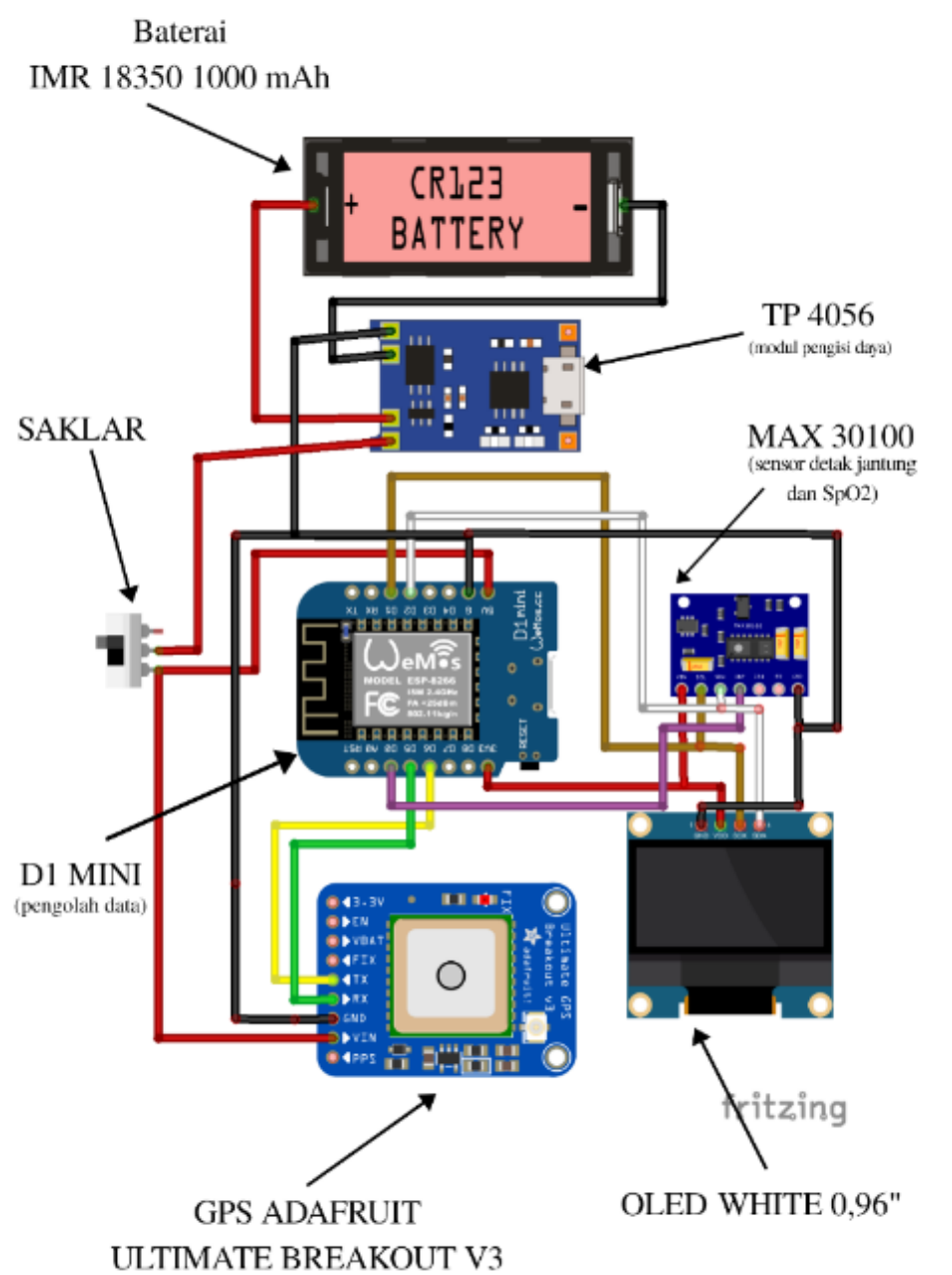

Gambar 5. Skema perangkat keras

Dari skema wiring Gambar 5 kemudian perangkat dirangkai dan disusun agar dapat digunakan di pergelangan tangan agar dapat digunakan saat beraktifitas seperti Gambar 6 . 


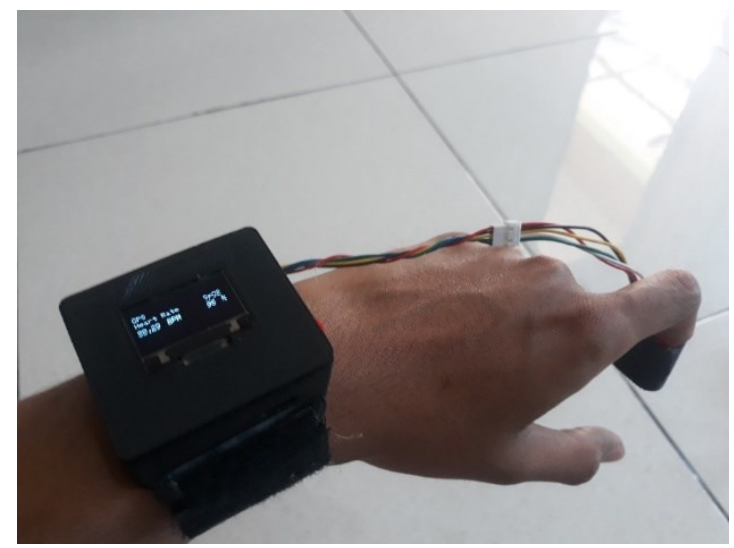

Gambar 6. Prototipe yang digunakan

\subsection{Kalibrasi GPS}

Proses kalibrasi GPS Adafruit Ultimate pada penelitian ini menggunakan dua metode yaitu pengukuran menggunakan fitur pengukuran pada Google Earth seperti pada Gambar 7 dan Rumus Haversine pada Persamaan (1) [4]. Kedua metode pengukuran tersebut digunakan untuk mencari selisih jarak koordinat yang diperoleh GPS Adafruit Ultimate dan GPS smartphone saat kondisi alat di dalam dan di luar ruangan.

$$
\text { Haversine }=2 r \sin ^{-1}\left(\sqrt{\sin ^{2}\left(\frac{\emptyset_{2}-\emptyset_{1}}{2}\right)+\cos \left(\emptyset_{1}\right) \cos \left(\emptyset_{2}\right) \sin ^{2}\left(\frac{\varphi_{2}-\varphi_{1}}{2}\right)}\right)
$$

\section{Keterangan :}

$r=$ Konstanta radius bumi $(6378,14 \mathrm{~km})$

$\emptyset_{1}=$ Latitude GPS Adafruit Ultimate

$\varphi_{1}=$ Longitude GPS Adafruit Ultimate

$\emptyset_{2}=$ Latitude GPS smartphone

$\varphi_{2}=$ Longitude GPS smartphone

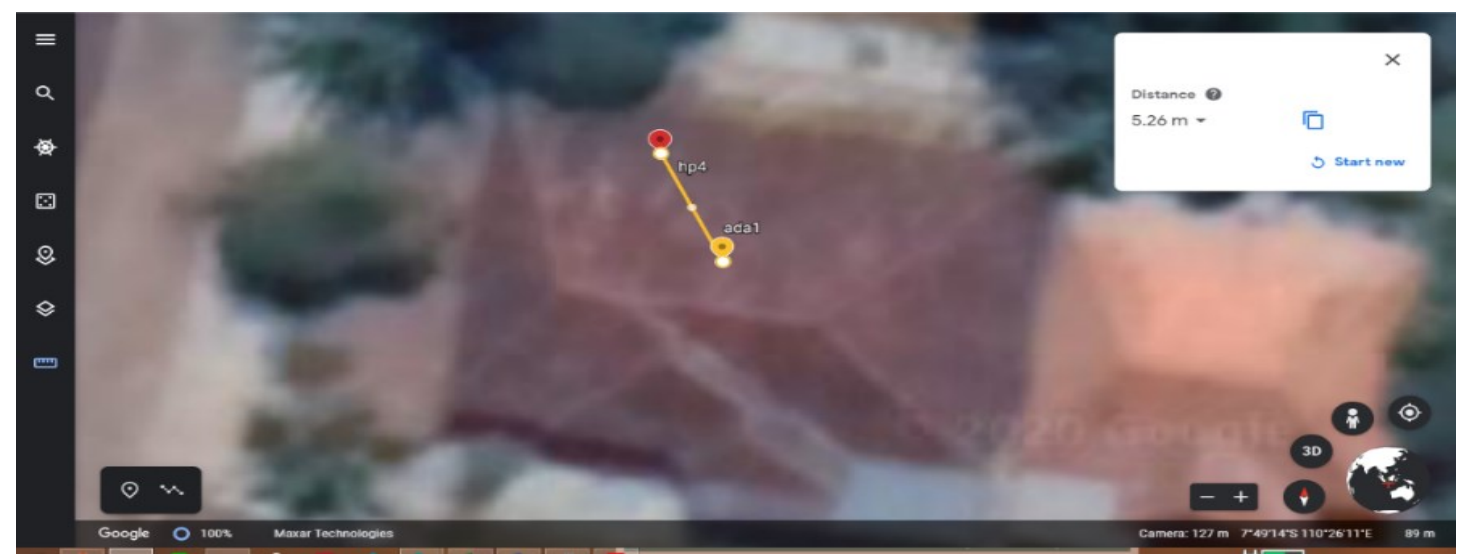

Gambar 7. Fitur pengukuran di Google Earth

Koordinat smartphone diperoleh dari Google Earth dalam bentuk degrees dan digunakan sebagai acuan pembanding. Penggunaan GPS pada smartphone digunakan untuk mengetahui koordinat lokasi saat pengujian. Akurasi GPS pada smartphone pernah diteliti sebelumnya ditampilkan pada Tabel 1 . 
Tabel 1. Penelitian Akurasi GPS Smartphone [4,5]

\begin{tabular}{l|l|l}
\hline Tahun & Penulis & Keterangan \\
\hline \multirow{2}{*}{2018} & $\begin{array}{l}\text { M. Fatoni } \\
\text { Anggris dkk }\end{array}$ & $\begin{array}{l}\text { Membandingkan GPS smartphone menggunakan Garmin GPS Oregon } \\
\text { 550 dan mendapatkan selisih jarak tertinggi sekitar 4.039 meter }\end{array}$ \\
\hline 2019 & $\begin{array}{l}\text { Andhy } \\
\text { Sulistyo dkk }\end{array}$ & $\begin{array}{l}\text { Melakukan penelitian tentang GPS smartphone dengan selisih akurasi } \\
\text { sekitar 2-3 meter }\end{array}$ \\
\hline
\end{tabular}

Tujuan kalibrasi GPS adalah untuk mengetahui akurasi GPS Adafruit Ultimate berdasarkan GPS smartphone dengan parameter jenis kondisi GPS di dalam dan di luar ruangan serta membandingkan hasil pengukuran selisih koordinat menggunakan dua metode tersebut.

\subsection{Kalibrasi $H R$}

Kalibrasi membandingkan data $H R$ yang dibaca oleh sensor MAX30100 dengan penghitungan detak jantung secara manual. Penghitungan detak jantung manual dilakukan dengan menghitung jumlah detak jantung pada pergelangan tangan kiri subjek dengan waktu perhitungan selama 15 detik. Subjek dipilih untuk mengetahui perbedaan $H R$ anak di bawah 10 tahun dengan umur di atas 10 tahun dalam kondisi duduk untuk mendapatkan hasil pembacaan sensor yang stabil.

Untuk menghitung detak jantung manual dapat menggunakan Persamaan (2) [6].

$$
B P M=\frac{60}{\text { waktu perhitungan }} \times \text { jumlah detak jantung }
$$

waktu perhitungan $=$ waktu yang digunakan saat penghitungan detak jantung jumlah detak jantung $=$ jumlah detak jantung yang diperoleh dalam waktu perhitungan

Tujuan kalibrasi $H R$ adalah untuk mengetahui selisih rata-rata sepuluh nilai yang diperoleh sensor dengan rata-rata pengukuran manual dalam 60 detik. Selisih nilai yang didapat kemudian digunakan untuk menghitung nilai Akurasi dalam bentuk persentase menggunakan Persamaan (3).

$$
\text { Nilai Akurasi }(\%)=100 \%-\left|\frac{\text { Selisih }}{\text { Manual }}\right| \times 100 \%
$$

\subsection{Kalibrasi SpO2}

Proses Kalibrasi SpO2 dilakukan pada 6 subjek saat kondisi duduk untuk mendapatkan hasil pembacaan sensor yang stabil. Kalibrasi ini dimaksudkan untuk mengetahui selisih ratarata sepuluh nilai yang didapatkan oleh sensor dan alat pembanding (alat komersial) sehingga didapatkan selisih dan nilai akurasinya. Alat komersil yang digunakan sebagai acuan merupakan alat yang telah memiliki ijin edar oleh KEMENKES RI.

Hasil yang didapatkan lalu dibandingkan dengan data pembacaan MAX30100 dan dihitung akurasinya menggunakan Persamaan (4).

$$
\text { Nilai Akurasi }(\%)=100 \%-\left|\frac{\text { Selisih }}{\text { Alat komersial }}\right| \times 100 \%
$$




\section{Hasil dan Pembahasan}

\subsection{Hasil Kalibrasi GPS}

Koordinat GPS yang diperoleh saat didalam ruangan ditampilkan pada Tabel 2 dan selisih pengukuran koordinat menggunakan dua metode ditampilkan pada Tabel 3.

Tabel 2. Koordinat GPS Di Dalam Ruangan

\begin{tabular}{c|c|c|c|c}
\hline \multirow{2}{*}{$\begin{array}{c}\text { Data } \\
\text { Ke }-\end{array}$} & \multicolumn{2}{|c|}{ Koordinat GPS Adafruit Ultimate } & \multicolumn{2}{c}{ Koordinat GPS Smartphone } \\
\cline { 2 - 5 } & latitude & longitude & latitude & longitude \\
\hline 1 & $-7,8205266$ & 110,4366684 & $-7,820526$ & 110,4366774 \\
\hline 2 & $-7,8205447$ & 110,4366226 & $-7,8205681$ & 110,4366543 \\
\hline 3 & $-7,8205128$ & 110,4366837 & $-7,8204699$ & 110,4366637 \\
\hline
\end{tabular}

Tabel 3. Pengukuran Selisih Koordinat GPS Di Dalam Ruangan

\begin{tabular}{c|c|c|c|c}
\hline \multirow{2}{*}{ Metode Pengukuran } & \multicolumn{3}{|c|}{ Data Ke - } & Rata-rata Selisih \\
\cline { 2 - 5 } & $\begin{array}{c}1 \\
\text { (meter) }\end{array}$ & $\begin{array}{c}2 \\
\text { (meter) }\end{array}$ & $\begin{array}{c}3 \\
\text { (meter) }\end{array}$ & \\
\hline Google Earth & 1,03 & 4,34 & 5,26 & 3,54 \\
\hline Rumus Haversine & 0,9948 & 4,3598 & 5,2604 & 3,34 \\
\hline
\end{tabular}

Pada Tabel 2 merupakan hasil data koordinat yang didapat saat kedua GPS berada di dalam ruangan. Selisih jarak koordinat terjauh dilihat pada Tabel 3 adalah 5,2604 meter yang diukur menggunakan Rumus Haversine dengan rata-rata selisih 3,34 meter dan 4,34 meter diukur menggunakan fitur pengukuran jarak yang tersedia pada Google Earth dengan rata-rata selisih 3,54 meter.

Koordinat GPS yang diperoleh saat di luar ruangan ditampilkan pada Tabel 4 dan selisih pengukurannya ditampilkan pada Tabel 5.

Tabel 4. Koordinat GPS Di Luar Ruangan

\begin{tabular}{c|c|c|c|c}
\hline \multirow{2}{*}{$\begin{array}{c}\text { Data } \\
\text { Ke - }\end{array}$} & \multicolumn{2}{|c|}{ Koordinat GPS Adafruit Ultimate } & \multicolumn{2}{c}{ Koordinat GPS Smartphone } \\
\cline { 2 - 5 } & latitude & longitude & latitude & longitude \\
\hline 1 & $-7,820673$ & 110,4366455 & $-7,8206742$ & 110,4366539 \\
\hline 2 & $-7,8206801$ & 110,4366302 & $-7,8207076$ & 110,4366128 \\
\hline 3 & $-7,8206682$ & 110,4366684 & $-7,8206677$ & 110,4366372 \\
\hline
\end{tabular}

Tabel 5. Pengukuran Selisih Koordinat GPS Di Luar Ruangan

\begin{tabular}{c|c|c|c|c}
\hline \multirow{2}{*}{ Metode Pengukuran } & \multicolumn{3}{|c|}{ Data Ke - } & Rata-rata Selisih \\
\cline { 2 - 4 } & $\begin{array}{c}1 \\
\text { (meter) }\end{array}$ & $\begin{array}{c}2 \\
\text { (meter) }\end{array}$ & $\begin{array}{c}3 \\
\text { (meter) }\end{array}$ & \\
\hline Google Earth & 0,99 & 3,6 & 3,54 & 2,71 \\
\hline Rumus Haversine & 0,9360 & 3,6130 & 3,4413 & 2,66 \\
\hline
\end{tabular}

Tabel 4 merupakan data koordinat yang didapat saat kedua GPS berada diluar ruangan. Selisih jarak terjauh pada Tabel 5 menggunakan perhitungan Haversine sebesar 3,6130 meter dengan rata-rata selisih 2,66 meter sedangkan pengukuran menggunakan metode Google Earth memiliki selisih jarak paling jauh 3,6 meter dan rata-rata selisih 2,71 meter. 
Hasil pengukuran menggunakan Google Earth maupun Rumus Haversine saat posisi GPS di dalam ruangan memiliki selisih jarak lebih besar (3,54 $\mathrm{m}$ dan 3,34 $\mathrm{m})$ daripada selisih pengukuran saat GPS berada di luar ruangan $(2,71 \mathrm{~m}$ dan 2,66 m). Pengukuran menggunakan metode Google Earth memiliki selisih dengan Haversine dikarenakan, saat peletakan titik awal dan akhir pada fitur pengukuran jarak yang terdapat di Google Earth dilakukan secara manual. Sedangkan pengukuran menggunakan Rumus Haversine merupakan persamaan yang sangat akurat untuk menghitung jarak antara dua titik di bumi secara panjang garis lurus tanpa mengabaikan kelengkungan bumi.

\subsection{Hasil Kalibrasi HR}

Kalibrasi HR MAX30100 berdasarkan perhitungan manual menggunakan beberapa subjek dalam kondisi santai (duduk). Hasil data yang didapat kemudian dihitung selisih dan nilai akurasinya seperti pada Tabel 6, sedangkan grafik data pembacaan HR MAX30100 ditunjukkan oleh Gambar 8.

Tabel 6. Data Hasil Kalibrasi $H R$

\begin{tabular}{c|c|c|c|c|c}
\hline \multirow{2}{*}{$\begin{array}{c}\text { Usia } \\
\text { (Tahun) }\end{array}$} & \multirow{2}{*}{ Jenis Kelamin } & \multicolumn{2}{|c|}{ HR (BPM) } & \multirow{2}{*}{$\begin{array}{c}\text { Selisih } \\
\text { Nilai Akurasi } \\
(\%)\end{array}$} \\
\cline { 3 - 4 } & & $\begin{array}{c}\text { Rata-rata } \\
\text { MAX30100 }\end{array}$ & Manual & & 98,21 \\
\hline 5 & L & 110 & 112 & 2 & 98,39 \\
\hline 6 & P & 110,2 & 112 & 1,8 & 99,04 \\
\hline 8 & L & 103 & 104 & 1 & 95,27 \\
\hline 9 & L & 106,7 & 112 & 5,3 & 99,21 \\
\hline 18 & L & 75,4 & 76 & 0,6 & 99,25 \\
\hline 39 & P & 79,4 & 80 & 0,6 & 98,23 \\
\hline \multicolumn{2}{|c|}{ Rata-rata }
\end{tabular}

Tabel 7. Data Pembacaan HR MAX30100

\begin{tabular}{c|c|c|c|c|c|c|c|c|c|c|c|c}
\hline Usia & Jenis & \multicolumn{10}{|c}{$H R$ MAX30100 (BPM) } & \multirow{2}{*}{ Rata-rata } \\
\cline { 3 - 14 } (Tahun) & Kelamin & 1 & 2 & 3 & 4 & 5 & 6 & 7 & 8 & 9 & 10 & \\
\hline 5 & $\mathrm{~L}$ & 115 & 112 & 120 & 111 & 108 & 113 & 118 & 115 & 117 & 77 & 110 \\
\hline 6 & $\mathrm{P}$ & 102 & 103 & 96 & 106 & 114 & 121 & 119 & 116 & 117 & 108 & 110,2 \\
\hline 8 & $\mathrm{~L}$ & 105 & 105 & 100 & 99 & 98 & 95 & 105 & 100 & 95 & 128 & 103 \\
\hline 9 & $\mathrm{~L}$ & 88 & 116 & 103 & 77 & 119 & 118 & 113 & 118 & 95 & 120 & 106,7 \\
\hline 18 & $\mathrm{~L}$ & 69 & 77 & 80 & 104 & 73 & 69 & 70 & 68 & 76 & 68 & 75,4 \\
\hline 39 & $\mathrm{P}$ & 77 & 76 & 79 & 80 & 75 & 78 & 80 & 81 & 82 & 86 & 79,4 \\
\hline
\end{tabular}

Pada Tabel 7 terdapat sepuluh data yang diperoleh dari sensor MAX30100 yang kemudian dihitung nilai rata-ratanya lalu dibandingkan dengan penghitungan manual. Ratarata data pada Tabel 7 digunakan karena nilai yang diperoleh sensor bersifat acak saat mendeteksi pulse, berbeda dengan penghitungan manual yang konstan selama 60 detik. Berdasarkan padaTabel 6 , nilai akurasi paling rendah sebesar $95,27 \%$ dan paling tinggi 99,25\%. Rata-rata nilai akurasi HR sebesar 98,23\%. Hal ini terjadi karena sensor MAX30100 membaca pulse pada subjek, pada saat sensor melakukan pembacaan dan subjek melakukan pergerakan, terutama jari yang digunakan untuk peletakan sensor, mengakibatkan nilai sensor naik turun. 


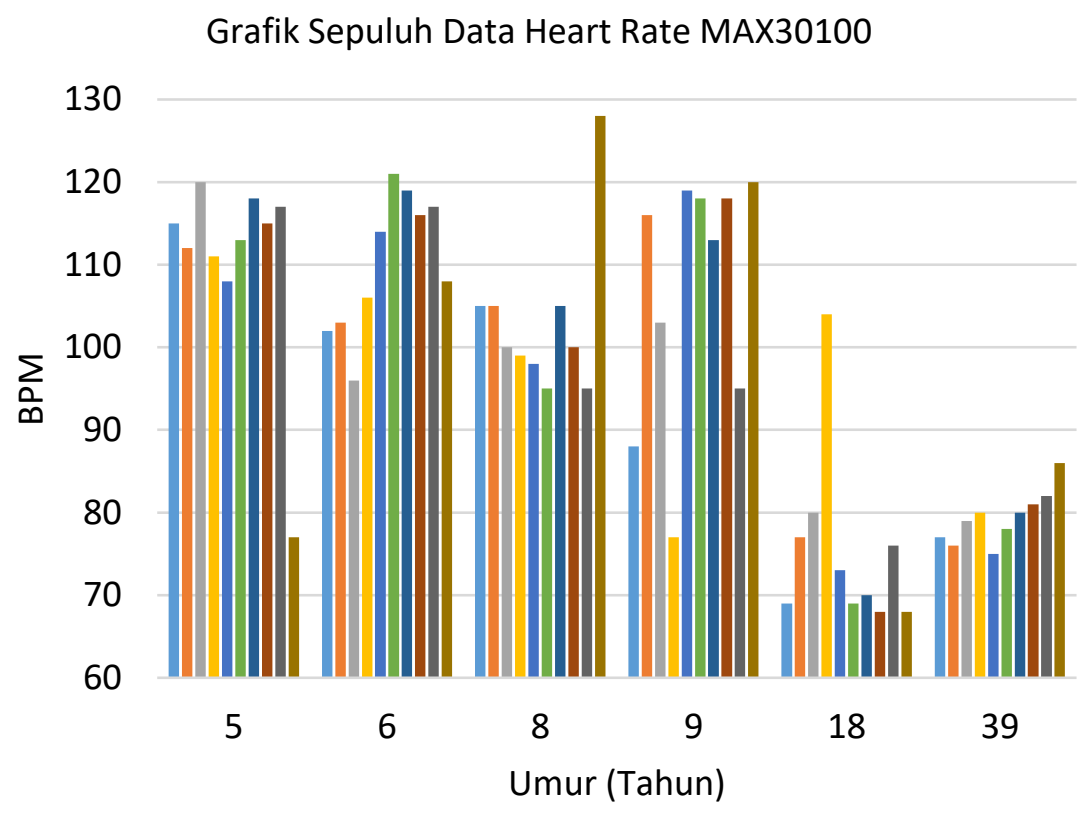

Gambar 8. Grafik data pembacaan HR MAX30100

\subsection{Hasil Kalibrasi SpO2}

Berdasarkan Tabel 8, dapat dilihat perubahan $\mathrm{SpO} 2$ terjadi pada subjek dalam kondisi duduk. Tabel 9 merupakan sepuluh data yang didapatkan oleh sensor MAX30100 saat mengalami perubahan nilai dan nilai yang diperoleh dari alat komersial lalu ditampilkan dalam bentuk grafik seperti Gambar 9.

Tabel 8. Data Hasil Kalibrasi SpO2

\begin{tabular}{|c|c|c|c|c|c|}
\hline \multirow{2}{*}{$\begin{array}{c}\text { Usia } \\
\text { (Tahun) }\end{array}$} & \multirow[b]{2}{*}{ Jenis Kelamin } & \multicolumn{2}{|c|}{$\mathrm{SpO} 2(\%)$} & \multirow[b]{2}{*}{ Selisih } & \multirow[b]{2}{*}{$\begin{array}{c}\text { Nilai Akurasi } \\
(\%)\end{array}$} \\
\hline & & $\begin{array}{c}\text { Rata-rata } \\
\text { MAX30100 }\end{array}$ & $\begin{array}{c}\text { Alat } \\
\text { komersial }\end{array}$ & & \\
\hline 6 & $\mathrm{P}$ & 97 & 99 & 2 & 97,98 \\
\hline 8 & $\mathrm{P}$ & 97 & 99 & 2 & 97,98 \\
\hline 9 & $\mathrm{P}$ & 97 & 97 & 0 & 100 \\
\hline 13 & $\mathrm{~L}$ & 96 & 97 & 1 & 98,99 \\
\hline 21 & $\mathrm{P}$ & 98 & 98 & 0 & 100 \\
\hline 25 & $\mathrm{P}$ & 96 & 97 & 1 & 98,99 \\
\hline \multicolumn{4}{|c|}{ Rata-rata } & 1 & 98,99 \\
\hline
\end{tabular}

Pengukuran pada Tabel 8 diperoleh rata-rata nilai akurasi 98,99\%. Perubahan nilai $\mathrm{SpO} 2$ pada masing masing alat dipengaruhi oleh pergerakan subjek. Sehingga saat subjek melakukan pergerakan (pada jari yang diukur) maka, nilai dari kedua sensor tersebut akan berubah. Namun, perubahan pada alat komersial cenderung lebih lambat sehingga grafik yang ditampilkan terlihat rapi. 
Tabel 9. Data Pembacaan MAX30100

\begin{tabular}{|c|c|c|c|c|c|c|c|c|c|c|c|c|c|}
\hline \multirow{2}{*}{$\begin{array}{c}\text { Usia } \\
\text { (Tahun) }\end{array}$} & \multirow{2}{*}{$\begin{array}{c}\text { Jenis } \\
\text { Kelamin }\end{array}$} & \multirow{2}{*}{ Jenis Pengukuran } & \multicolumn{10}{|c|}{$H R$ (BPM) } & \multirow{2}{*}{$\begin{array}{l}\text { Rata- } \\
\text { rata }\end{array}$} \\
\hline & & & 1 & 2 & 3 & 4 & 5 & 6 & 7 & 8 & 9 & 10 & \\
\hline \multirow{2}{*}{6} & \multirow{2}{*}{$\mathrm{P}$} & MAX30100 & 99 & 98 & 97 & 99 & 97 & 96 & 97 & 96 & 95 & 96 & 97 \\
\hline & & Alat komersial & 99 & 99 & 99 & 99 & 99 & 99 & 99 & 99 & 99 & 99 & 99 \\
\hline \multirow{2}{*}{8} & \multirow{2}{*}{$\mathrm{P}$} & MAX30100 & 96 & 97 & 96 & 98 & 97 & 96 & 98 & 97 & 98 & 97 & 97 \\
\hline & & Alat komersial & 99 & 99 & 99 & 99 & 99 & 99 & 99 & 99 & 99 & 99 & 99 \\
\hline \multirow{2}{*}{9} & \multirow{2}{*}{$\mathrm{P}$} & MAX30100 & 96 & 98 & 97 & 96 & 98 & 96 & 98 & 97 & 96 & 98 & 97 \\
\hline & & Alat komersial & 98 & 98 & 98 & 96 & 96 & 96 & 97 & 97 & 97 & 97 & 97 \\
\hline \multirow{2}{*}{13} & \multirow{2}{*}{$\mathrm{L}$} & MAX30100 & 96 & 97 & 95 & 97 & 96 & 97 & 96 & 95 & 96 & 95 & 96 \\
\hline & & Alat komersial & 97 & 97 & 97 & 97 & 96 & 96 & 98 & 98 & 97 & 97 & 97 \\
\hline \multirow{2}{*}{21} & \multirow{2}{*}{$P$} & MAX30100 & 97 & 98 & 99 & 98 & 97 & 98 & 97 & 99 & 98 & 99 & 98 \\
\hline & & Alat komersial & 98 & 98 & 98 & 98 & 98 & 98 & 98 & 98 & 98 & 98 & 98 \\
\hline \multirow{2}{*}{25} & \multirow{2}{*}{$\mathrm{P}$} & MAX30100 & 97 & 98 & 96 & 95 & 96 & 95 & 97 & 95 & 96 & 95 & 96 \\
\hline & & Alat komersial & 97 & 97 & 97 & 97 & 97 & 97 & 97 & 97 & 97 & 97 & 97 \\
\hline
\end{tabular}

Grafik Sepuluh Data SpO2 Alat Komersial

100

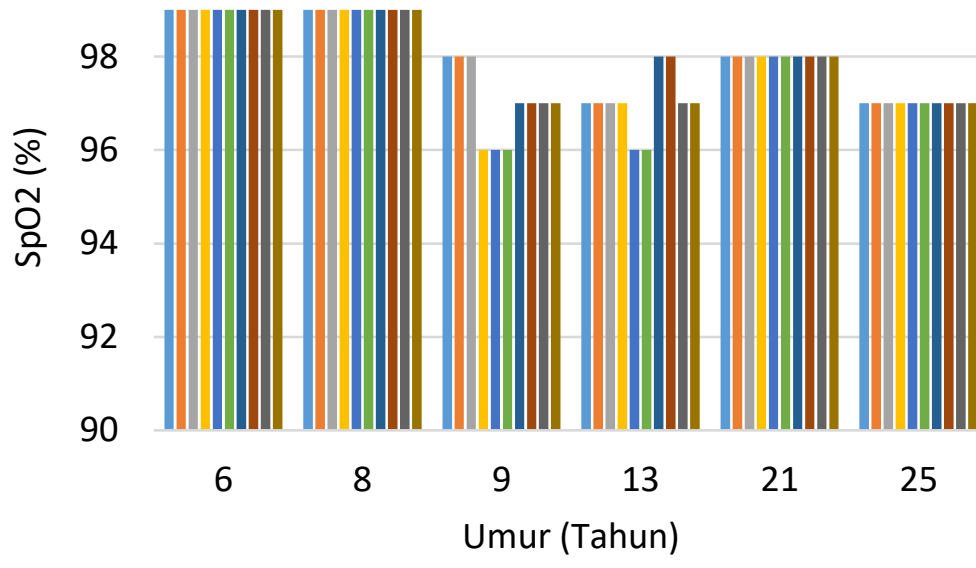

Grafik Sepuluh Data SpO2 MAX30100

100

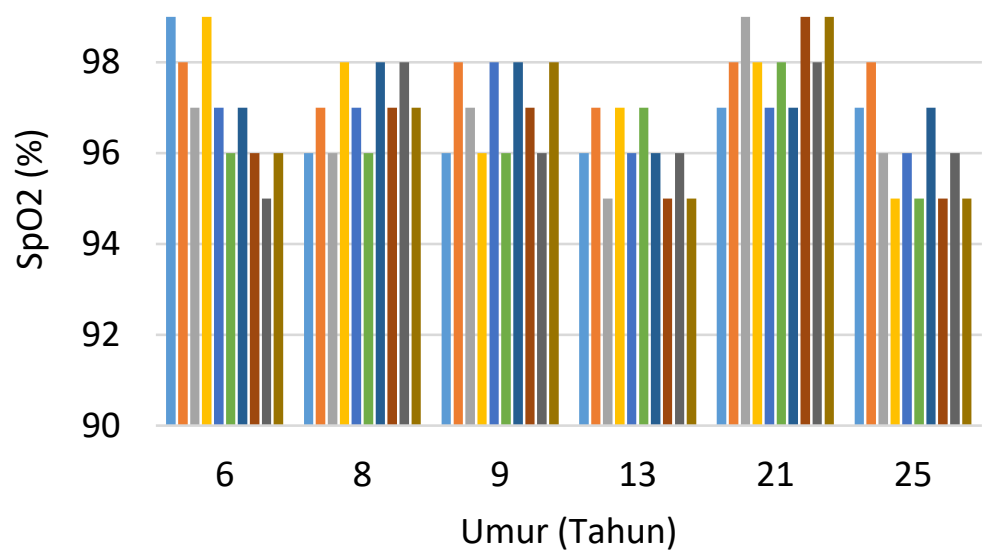

Gambar 9. Grafik data pembacaan $\mathrm{SpO} 2$ 


\subsection{Analisis Pengujian Prototipe}

\subsubsection{Waktu Tunggu GPS Mendapatkan Koordinat}

Waktu tunggu pada GPS Adafruit untuk mendapatkan data dari sinyal satelit sejak pertama kali dihidupkan dengan kondisi GPS tanpa penutup casing ditampilkan pada Tabel 10 dan kondisi GPS tertutup casing ditampilkan pada Tabel 11. Berdasarkan Tabel 10, dilaksanakan 4 kali pengujian dengan casing terbuka. Waktu tunggu rata-rata untuk mendapatkan sinyal adalah 4 menit, sedangkan waktu tunggu untuk mendapatkan koordinat adalah 9,5 menit. Pada saat casing tertutup, waktu tunggu untuk mendapatkan sinyal adalah 13 menit, sedangkan waktu tunggu untuk mendapatkan koordinat tidak dapat diperoleh. Hal tersebut dikarenakan pada saat casing tertutup, alat sama sekali tidak dapat memperoleh koordinat meskipun telah ditunggu pada waktu yang lama.

Tabel 10. Waktu tunggu kondisi casing terbuka

\begin{tabular}{c|c|c|c}
\hline \multirow{2}{*}{ Pengujian Ke- } & \multirow{2}{*}{ Kondisi casing } & \multicolumn{2}{|c}{ Waktu Tunggu (menit) } \\
\cline { 3 - 4 } & & Mendapatkan Sinyal & Mendapatkan Koordinat \\
\hline 1 & Terbuka & 3 & 10 \\
\hline 2 & Terbuka & 2 & 7 \\
\hline 3 & Terbuka & 8 & 13 \\
\hline 4 & Terbuka & 3 & 8 \\
\hline
\end{tabular}

Tabel 11. Waktu tunggu kondisi casing tertutup

\begin{tabular}{c|c|c|c}
\hline \multirow{2}{*}{ Pengujian Ke- } & \multirow{2}{*}{ Kondisi casing } & \multicolumn{2}{|c}{ Waktu Tunggu (menit) } \\
\cline { 3 - 4 } & & Mendapatkan Sinyal & Mendapatkan Koordinat \\
\hline 1 & Tertutup & 18 & - \\
\hline 2 & Tertutup & 12 & - \\
\hline 3 & Tertutup & 7 & - \\
\hline 4 & Tertutup & 15 & - \\
\hline
\end{tabular}
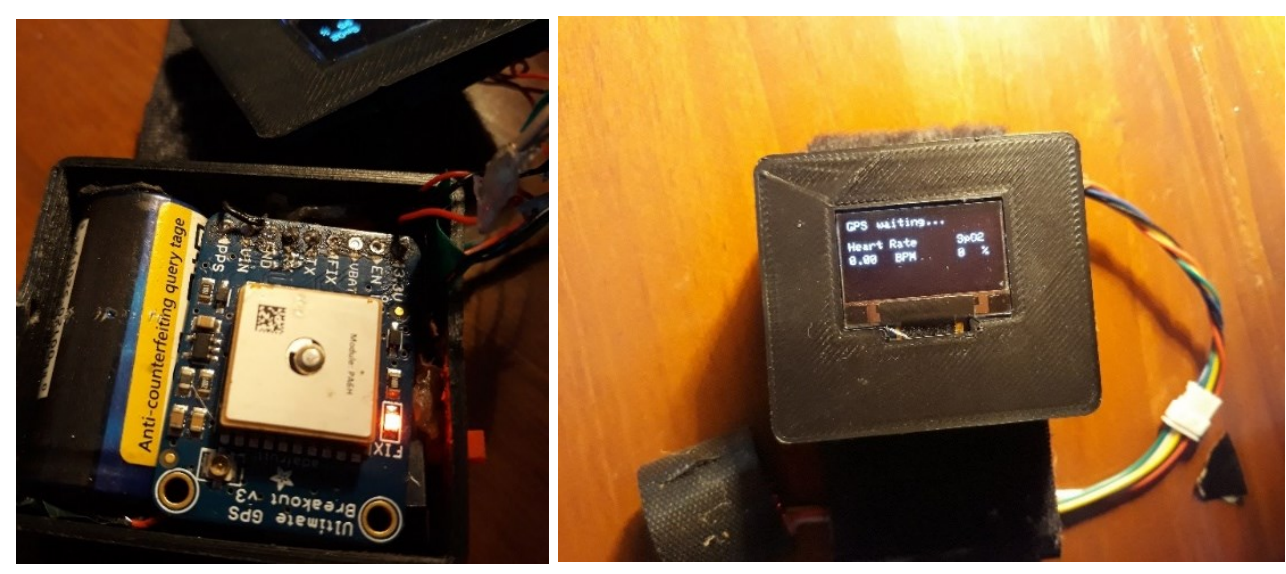

Gambar 10. Kondisi casing terbuka (kiri) dan casing tertutup (kanan)

Pada saat casing terbuka seperti Gambar 10, GPS mampu memperoleh sinyal lebih cepat karena antena GPS tidak memiliki penghalang. Untuk mengetahui status GPS sudah atau belum mendapatkan sinyal dan koordinat pada aplikasi Blynk ditampilkan pada beberapa widget. Saat prototipe pertama kali dihidupkan, status sinyal GPS seperti Gambar 11(a) karena GPS belum mendapatkan sinyal. Setelah mendapatkan sinyal, status sinyal GPS pada aplikasi Blynk akan berubah seperti Gambar 11(b). 


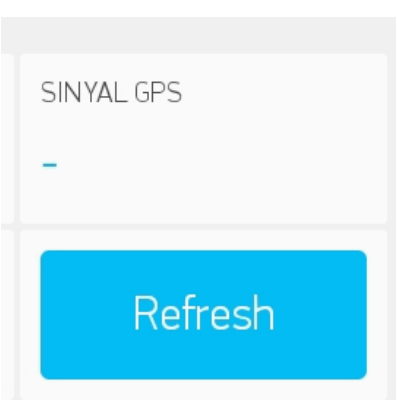

(a) saat belum mendapat sinyal GPS

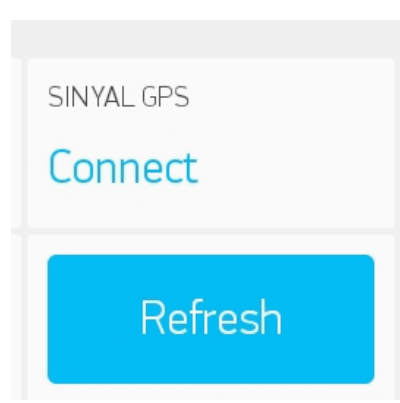

(a) saat sudah mendapat sinyal GPS

Gambar 11. Status sinyal GPS pada Blynk

Status GPS yang ditampilkan pada prototipe saat GPS belum mendapatkan sinyal ditampilkan Gambar 12(a). Sedangkan saat memperoleh sinyal ditampilkan seperti Gambar 12(b).

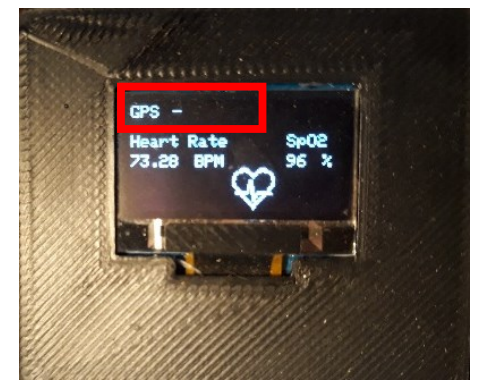

(a) sebelum mendapatkan sinyal GPS

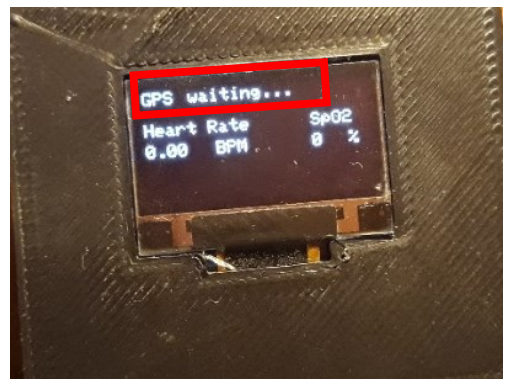

(b) setelah mendapatkan sinyal GPS

Gambar 12. Status GPS pada prototipe

Saat GPS mendapatkan data koordinat akan ditampilkan pada Blynk seperti Gambar 13(a). Sedangkan pada prototipe akan ditampilkan seperti Gambar 13(b).

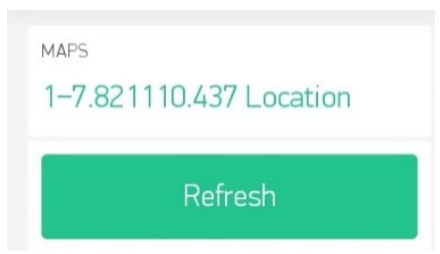

(a) pada Blynk

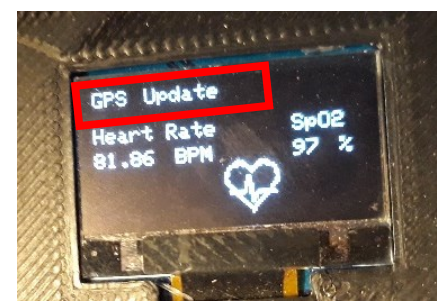

(b) pada prototipe

Gambar 13. Status GPS saat mendapatkan data koordinat pada prototipe

Perbandingan waktu tunggu pada GPS Adafruit saat di dalam dan di luar ruangan ditunjukkan oleh tabel 12 dan Tabel 13 secara berturut-turut adalah untuk keadaan casing terbuka dan casing tertutup. Pada saat keadaan casing terbuka, waktu tunggu rata-rata untuk mendapatkan sinyal di dalam ruangan 120 detik atau 2 menit. Sedangkan waktu tunggu ratarata untuk mendapatkan sinyal di luar ruangan adalah 59 detik. Terdapat selisih sekitar 61 detik atau 1 menit 1 detik antara di dalam dan luar ruangan saat casing terbuka untuk mendapatkan sinyal. Sesuai dengan teori, bahwa sinyal akan didapat lebih cepat saat di luar ruangan telah 
terbukti dengan selisih waktu sekitar 2 kali lebih cepat di luar ruangan dibandingkan di dalam ruangan. Untuk mendapatkan koordinat pada casing terbuka, diperoleh selisih waktu yang cukup signifikan di dalam dan luar ruangan. Waktu tunggu mendapatkan koordinat di dalam ruangan rata-rata adalah 585 detik atau 9,75 menit, sedangkan di luar ruangan waktu tunggu rata-rata sekitar 80 detik atau 1,3 menit. Selisih mendapatkan koordinat pada casing terbuka saat di dalam dan luar ruangan sekitar 8,45 menit lebih cepat di luar ruangan. Hal tersebut dikarenakan tidak adanya halangan berupa tembok dan yang lainnya sehingga GPS dapat lebih cepat mendapatkan koneksi ke satelit.

Pada saat casing tertutup, untuk mendapatkan sinyal, diperoleh selisih yang signifikan di dalam dan luar ruangan sesuai dengan Tabel 13. Waktu tunggu mendapatkan sinyal di dalam ruangan rata-rata adalah 780 detik atau 13 menit, sedangkan di luar ruangan waktu tunggu ratarata sekitar 106 detik atau 1,7 menit. Selisih waktu mendapatkan sinyal pada casing tertutup di dalam dan luar ruangan sekitar 11,3 menit lebih cepat di luar ruangan. Waktu tunggu untuk mendapatkan koordinat pada casing tertutup tidak dapat diperoleh. Hal tersebut dikarenakan pada saat casing tertutup, alat sama sekali tidak dapat memperoleh koordinat meskipun telah ditunggu pada waktu yang lama.

Tabel 12. Waktu Tunggu Keadaan Casing Terbuka

\begin{tabular}{c|c|c|c|c}
\hline \multirow{2}{*}{ Pengujian Ke- } & \multicolumn{2}{|c|}{$\begin{array}{c}\text { Waktu Tunggu (detik) } \\
\text { Mendapatkan Sinyal }\end{array}$} & \multicolumn{2}{c}{$\begin{array}{c}\text { Waktu Tunggu (detik) } \\
\text { Mendapatkan Koordinat }\end{array}$} \\
\cline { 2 - 5 } & Dalam Ruangan & Luar Ruangan & Dalam Ruangan & Luar Ruangan \\
\hline 1 & 120 & 56 & 720 & 111 \\
\hline 2 & 120 & 130 & 360 & 145 \\
\hline 3 & 180 & 10 & 780 & 10 \\
\hline 4 & 60 & 40 & 480 & 53 \\
\hline
\end{tabular}

Tabel 13. Waktu Tunggu Keadaan Casing Tertutup

\begin{tabular}{c|c|c|c|c}
\hline \multirow{2}{*}{ Pengujian Ke- } & \multicolumn{2}{|c|}{$\begin{array}{c}\text { Waktu Tunggu (detik) } \\
\text { Mendapatkan Sinyal }\end{array}$} & \multicolumn{2}{c}{$\begin{array}{c}\text { Waktu Tunggu (detik) } \\
\text { Mendapatkan Koordinat }\end{array}$} \\
\cline { 2 - 5 } & Dalam Ruangan & Luar Ruangan & Dalam Ruangan & Luar Ruangan \\
\hline 1 & 1080 & 77 & - & - \\
\hline 2 & 420 & 152 & - & - \\
\hline 3 & 720 & 46 & - & - \\
\hline 4 & 900 & 147 & - & - \\
\hline
\end{tabular}

\subsubsection{Pengujian Notifikasi Detak Jantung >100 BPM}

Pada Tabel 14 ditampilkan hasil pengujian notifikasi terhadap subjek apabila sensor membaca detak jantung kurang dari 60 dan lebih dari 100 BPM. Dikarenakan rekayasa untuk subjek yang memiliki detak jantung kurang dari 60 atau lebih dari 100 BPM cukup sulit, maka untuk pengujian menggunakan subjek yang berusia kurang dari 10 tahun. Notifikasi detak jantung tinggi berhasil dikirim ke pemantau dan pasien berdasarkan subjek di bawah 10 tahun untuk menguji notifikasi karena detak jantung normal subjek di atas 100 BPM. 
Tabel 14. Pengujian Notifikasi

\begin{tabular}{c|c|c|c}
\hline $\begin{array}{c}\text { Usia } \\
\text { (Tahun) }\end{array}$ & $\begin{array}{c}\text { Jenis } \\
\text { Kelamin }\end{array}$ & MAX30100 & Notifikasi \\
\hline 5 & L & 110 & Tinggi \\
\hline 6 & P & 110,2 & Tinggi \\
\hline 8 & L & 103 & Tinggi \\
\hline 9 & L & 106,7 & Tinggi \\
\hline 18 & L & 75,4 & - \\
\hline 39 & P & 79,4 & - \\
\hline
\end{tabular}

Tampilan notifikasi pada Blynk ditunjukkan pada Gambar 4 sedangkan tampilan pada Oled ditunjukkan pada Gambar 14.

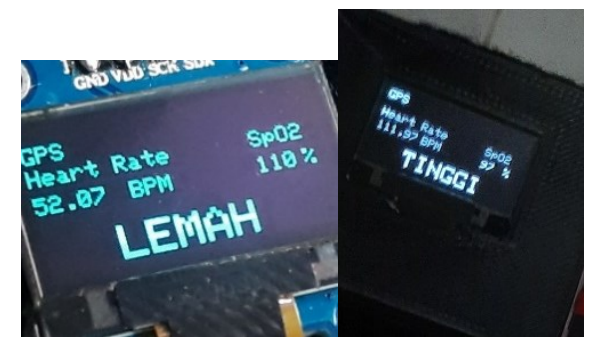

Gambar 14. Tampilan notifikasi Oled

\subsubsection{Penggunaan Prototipe Saat Beraktivitas}

Saat pasien duduk dan tidak melakukan banyak gerakan, data yang ditampilkan MAX30100 dapat dikatakan akurat seperti Gambar 15. Penggunaan prototipe saat berjalan atau melakukan banyak gerakan menyebabkan pembacaan sensor MAX30100 mengalami kekacauan (data yang diterima berubah signifikan) seperti pada Gambar 16.

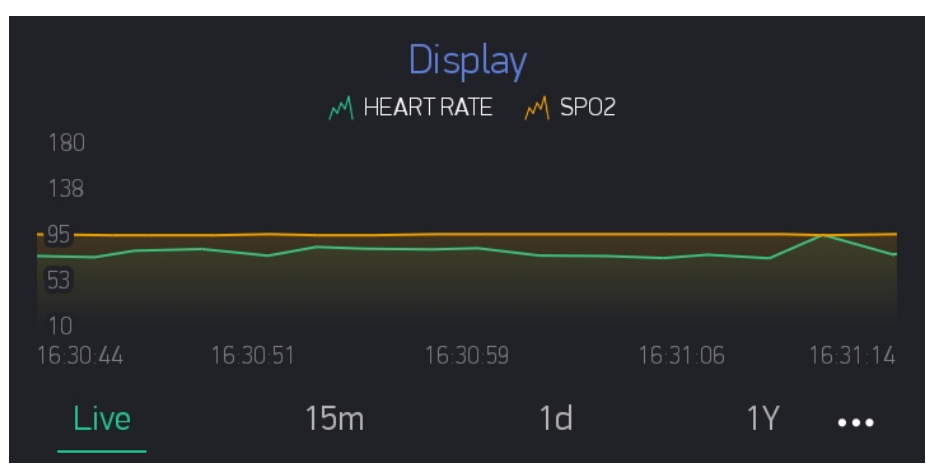

Gambar 15. Prototipe digunakan saat duduk

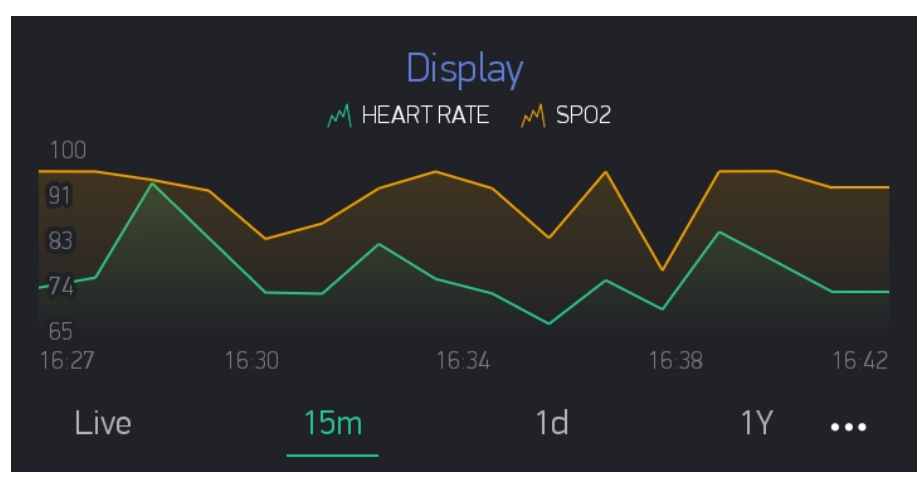

Gambar 16. Prototipe digunakan saat berjalan 


\subsubsection{Waktu Kerja Prototipe}

Waktu kerja prototipe setelah melakukan pengujian ditampilkan pada Tabel 15. Sensor MAX30100 akan berhenti update data ketika mengalami gangguan koneksi maupun gangguan dari pengkabelan. Saat mengalami gangguan dan sensor tidak update, prototipe harus dimuat ulang secara manual dengan mematikan saklar lalu dihidupkan lagi.

Tabel 15. Pengujian daya tahan dan pengisian baterai

\begin{tabular}{c|c}
\hline Pengujian & Lama (menit) \\
\hline Daya tahan baterai & 270 \\
\hline Pengisian baterai & 90 \\
\hline
\end{tabular}

\subsection{Analisis Akhir}

Prototipe membutuhkan acces point wifi untuk dapat digunakan. Pada saat pengujian, prototipe menggunakan Hotspot Seluler yang terdaftar dalam program sebagai acces point. Keakuratan GPS dapat dikatakan presisi karena berdasarkan pada kalibrasi GPS didalam maupun diluar ruangan diperoleh hasil selisih jarak kurang dari 7 meter dan untuk standar ketelitian posisi absolut sebesar 8-10 meter. Rata-rata nilai akurasi $H R$ dapat dikatakan akurat untuk digunakan sebagai pengukuran detak jantung pada pasien dalam kondisi duduk dan nilai detak jantung pada anak usia $<10$ tahun lebih tinggi daripada usia $>10$ tahun sesuai dengan tinjauan teori yang digunakan. Grafik pengukuran SpO2 pada alat komersial lebih stabil karena perubahan data pada alat tersebut tidak secepat perubahan data pada prototipe $[7,8]$.

GPS tidak mampu mendapatkan koordinat apabila antena GPS terhalangi oleh casing dalam ruang yang sempit. Saat GPS terhalangi gedung atau benda-benda padat lainnya dapat mempengaruhi kinerja GPS untuk mendapatkan sinyal koordinat, maka disarankan di tempat terbuka (tanpa penghalang). Pengiriman data ke pemantau memiliki delay selama 2 detik karena untuk mengantisipasi tabrakan data antara MAX30100 dan GPS saat pengiriman ke Blynk. Fitur notifikasi pada Blynk mengirim data notifikasi setiap 5 detik sekali apabila mendapatkan detak jantung di atas 100 BPM secara terus menerus. Waktu kerja prototipe yang singkat dan pengisian daya yang lama membuat prototipe ini perlu dikembangkan lagi $[9,10]$.

\section{Kesimpulan}

Berdasarkan perancangan, pengujian dan analisis hasil terhadap prototipe sistem pendeteksi lokasi dan kesehatan manusia berbasis IoT dapat ditarik beberapa kesimpulan. Koordinat yang diperoleh GPS Adafruit dapat dikatakan akurat karena memiliki selisih koordinat kurang dari 5 meter. Waktu tunggu yang dibutuhkan untuk mendapatkan sinyal dari satelit tidak menentu karena dipengaruhi oleh casing prototipe. Pada saat GPS tertutup casing, GPS tidak mampu memperoleh koordinat, sedangkan saat tidak tertutup, GPS memperoleh koordinat dalam waktu 7-13 menit. Pembacaan detak jantung oleh sensor MAX30100 didapatkan rata-rata akurasi sebesar 98,23\%. Namun, sensor tersebut memiliki kelemahan apabila digunakan untuk pergerakan, nilai yang dibaca naik turun. Pembacaan SpO2 MAX30100 didapatkan rata-rata akurasi sebesar 98,99\% sedangkan notifikasi >100 BPM berhasil dikirimkan dan diterima oleh pemantau maupun pasien.

Saran untuk penelitian selanjutnya adalah perbaikan cover atau pelindung sensor MAX30100 pada jari agar pada saat beraktifitas/bergerak data yang diterima tidak kacau. Selanjutnya perbaikan penggunaan bahan maupun ketebalan bahan yang digunakan pada prototipe mempengaruhi GPS dalam mendapatkan koordinat. Pada pengujian, alat pembanding kalibrasi HR sebaiknya menggunakan alat yang sejenis dengan nilai sensor diperoleh melalui pulse. 


\section{Daftar Pustaka}

[1] Wildian, \& Mardiansyah. (2019). Rancang Bangun Alat Monitoring Detak Jantung Pasien Rumah Sakit dengan Sistem Telemetri Berbasis Ardiuno UNO R3. Jurnal Fisika Unand, 8(4), 355-361.

[2] Qahar, A. N. (2018). Desain Alat Ukur Denyut Jantung Dan Saturasi Oksigen Pada Anak Menggunakan Satu Sensor. Universitas Islam Indonesia

[3] R, A., Nigli, K. S., \& P, M. K. (2020). Patient Health Monitoring System Based on IOT. UGC Care Journal, 40(60), 2553-2561.

[4] Anggris, M. F., Ananta, M. T., \& Az-zahra, H. M. (2018). Rancang Bangun Aplikasi Augmented Reality Pengelolaan Rambu-Rambu Lalu Lintas Menggunakan Global Positioning System ( GPS ) pada Android. Jurnal Pengembangan Teknologi Informasi dan Ilmu Komputer (J-PTIIK) Universitas Brawijaya, 2(8), 2892-2901.

[5] Sulistyo, A., Yudhana, A., Sunardi, \& Aini, R. (2019). Kombinasi Teknologi Aplikasi GPS Mobile dan Pemetaan SIG dalam Sistem Pemantauan Demam Berdarah ( DBD ). Khazanah Informatika, 5(1), 6-14.

[6] Yunidwianggraeni, Irawan, B., \& Saputra, R. E. (2017). Perancangan Alat Pendeteksi Denyut Nadi Pada Korban Bencana Alam Menggunakan Teknologi Jaringan Sensor Nikabel. E-Proceeding of Engineering: 4(3), 4083-4090.

[7] Pandhita, A. L., \& Yuliansyah, H. (2016). Rancang Bangun Aplikasi Android Berbasis Lokasi Untuk Pencarian Distribution Point. JURNAL INFOTEL - Informatika Telekomunikasi Elektronika, 7(2), 83-92.

[8] Oklilas, A. F., Siswanti, S. D., \& Rachman, M. D. (2017). Akurasi Pembacaan GPS Pada Android Untuk Location Based Service (Studi Kasus: Informasi Lokasi SMA di Palembang). Jurnal Ilmu Komputer dan Agri-Informatika, 4(1), 1.

[9] Prastowo, P. T., Satoto, K. I., \& Isnanto, R. (2012). Perancangan Aplikasi Pencari Masjid Menggunakan Global Positioning System (GPS) Pada Platform Android. TRANSIENT, $1,5$.

[10] Putri, D. I. K. (2015). Visualisasi dan Sinkronisasi data GPS Tracker Berbasis SMS Gateway. Institut Teknologi Sepuluh November. 